\title{
India versus Pakistan and the power of a six: an analysis of cricket results
}

\author{
Kamran Abbasi, Khalid S Khan
}

\section{See p 843}

BMJ

Kamran Abbasi

deputy editor

Education Resource

Centre,

Birmingham

Women's Health

Care NHS Trust

Birmingham

Khalid S Khan

consultant in

obstetrics and

gynaecology

Correspondence to:

K Abbasi

kabbasi@bmj.com

BMJ 2004;328:800
To paraphrase CLR James, "What do they know of South Asia who do not cricket know?" George Orwell described sport as war minus the shooting. South Asian cricket has been dubbed war minus the nuclear missiles. The result of a sports match can trigger cardiac deaths, ${ }^{1}$ and contests between India and Pakistan have prompted shootings, riots, killings, and sudden death. Cricket has been used as an extension of foreign policy-to instigate peace or prolong hostilities. However, regional cooperation will probably increase prosperity, with some commentators arguing that cricket is an important component of public health strategies. ${ }^{2}$

Facing up to the future requires a dispassionate appraisal of the past. How have India and Pakistan fared against each other in cricket? To answer this questionuppermost in the minds of over a billion people in South Asia and many millions outside-we compared 50 years of test matches and one day matches between India and Pakistan. One incident galvanised the emotions of these two nations. In 1986 Pakistan batsman Javed Miandad scored a dramatic match-winning six off the last ball in a one day match that his side had looked like losing until that delivery - a shot heard throughout South Asia and much of the world. The burning question since has been what effect Miandad's six - a reference point in South Asia to rival John F Kennedy's shooting and the winning baseball strike in Don DeLillo's Underworld - had on the subsequent performance of the teams? Could analysis of results before and

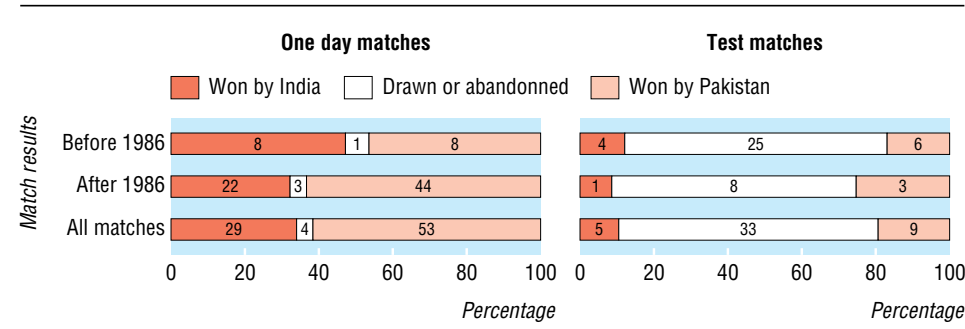

An upward slope favours Pakistan, a downward slope favours India

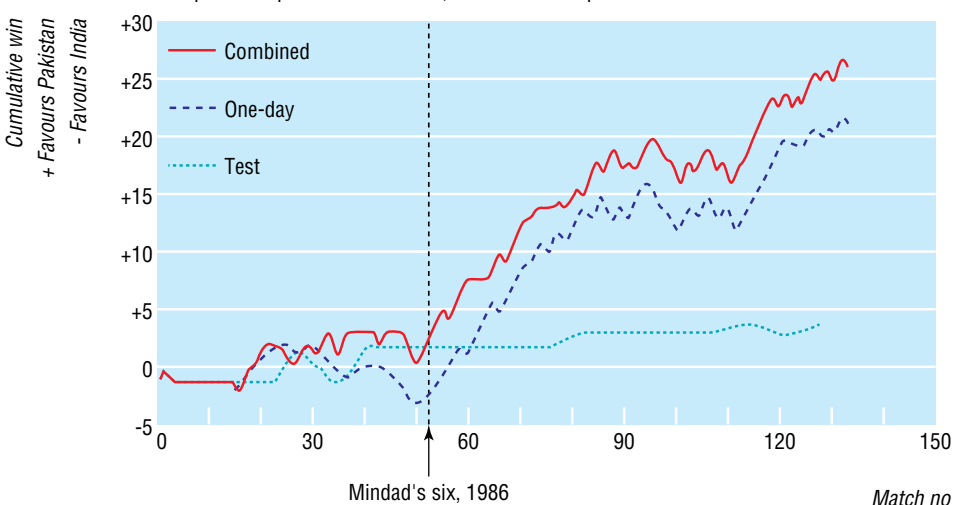

Match results according to match type and time period (before and after Miandad's match-winning six). Results presented as $100 \%$ stacked bar charts with number of matches included as figures in the stacks. Cumulative win chart sums up the results over time, with an increase by 1 indicating a Pakistan win and a decrease by 1 indicating an Indian win after this reference point answer the question, end conjecture, and allow peace to blossom?

\section{Methods and results}

We analysed all 133 matches between 1952 and 2003. There were 47 test matches and 86 one day matches. India won five $(11 \%)$ test matches and $30(35 \%)$ one day internationals, and Pakistan won nine $(19 \%)$ and $52(60 \%)$ respectively. The rest were drawn, or abandoned because of bad weather, crowd trouble, or assassination. We grouped matches into time periods 1952-86 (35 test and 17 one day matches) and 1986-2003 (12 test and 69 one day matches) according to our specified time point-Miandad's six. We examined the relation between match results and time periods by cross tabulation and assessed the strength of association (Kendall's rank correlation).

Overall, Pakistan was more likely to win after the hit (correlation coefficient $\tau=0.17, \quad \mathrm{P}=0.03$ ). Venue (home, away, or neutral) was not associated with outcome ( $\tau=0.01, \mathrm{P}=0.82$ ), and neither was winning the toss $(\tau=0.06, \mathrm{P}=0.44)$ or batting first $(\tau=0.04$, $\mathrm{P}=0.55)$. In the cumulative win chart, the steep upward slope for one day matches after 1986 highlights the change in fortunes in Pakistan's favour (figure).

\section{Comment}

Overall, Pakistan has achieved greater success in both forms of the game. These data suggest that in one day matches Miandad's six inspired an improvement in Pakistan's performance or a decline in India's, or both, but this effect was small in test cricket. Venue, winning the toss, and batting first were not associated with outcome. We believe there are no other important explanations for the observed findings. Both teams have won one World Cup final and lost one. No other factors were at play around our reference point that might have favoured one team over the other, certainly not in terms of retirements or rule or format changes. Weather conditions, ground conditions, selection policies, and match fixes are too innumerable to measure or adjust for. We believe these data support our hypothesis that a single shot had an enduring influence. Now India must have a landmark victory of its own-it may have already.

Contributors: KA conceived the study, supplied the hypothesis, advised on the analysis, and wrote and edited the manuscript. KSK helped formulate the hypothesis, performed the analysis, and wrote and edited the manuscript. Christopher Martyn ridiculed the analysis before offering a little sensible advice. KA is guarantor.

Funding: None.

Competing interests: Both KA and KSK fail the Tebbit Test in favour of Pakistan, closely followed by India.

1 Witte DR, Bots ML, Hoes AW, Grobbee DE. Cardiovascular mortality in Dutch men during 1996 European football championship: longitudinal population study. BMJ 2000;321:1552-4.

2 Shafqat S, Barucha N. Is cricket the magic glue that unites South Asia? BMJ 2004;328:843. 